\title{
Effect of year of study on stress levels in male undergraduate dental students
}

This article was published in the following Dove Press journal:

Advances in Medical Education and Practice

17 October 2013

Number of times this article has been viewed

\author{
Abdullah M Alzahem' \\ Henk T Van der Molen ${ }^{2}$ \\ Benjamin J De Boer ${ }^{3}$ \\ 'Advanced Education in General \\ Dentistry (AEGD) Residency \\ Program, King Abdullah International \\ Medical Research Center/King \\ Saud bin Abdulaziz University for \\ Health Sciences/National Guard \\ Health Affairs, Riyadh, Saudi Arabia; \\ ${ }^{2}$ Institute of Psychology, Faculty of \\ Social Sciences, Erasmus University, \\ Rotterdam, The Netherlands; ${ }^{3}$ Clinical \\ Psychology, Princess Nora University, \\ Riyadh, Saudi Arabia
}

Objective: Stress among dental students can be a significant threat, resulting in physical and/or mental illness, and have a negative effect on students' performance and the professional practice of dentistry. Stress can occur from different sources. The purpose of this study is to test whether the year of study has an effect on the stress levels of dental students.

Method: Our study consisted of a cross-sectional survey using a modified version of the Dental Environment Stress (DES) questionnaire. The questionnaires were filled out by male undergraduate dental students at King Saud University in Riyadh City during the 2010-2011 academic year $(\mathrm{n}=214)$.

Results: The results show the most common sources of stress: examinations and completing clinical requirements. Moreover, in the five-year lecture-based traditional curriculum, the third year students reported the highest level of stress, whereas the first year reported the lowest level of stress.

Conclusion: Third year undergraduate dental students reported the highest level of stress. This stress could be reduced by reviewing and modifying the dental curriculum by allowing students to have contact with patients more gradually, starting from the first year, in addition to adding stress prevention and intervention programs in dental curricula.

Keywords: dental, education, students, stress, study year

\section{Introduction}

The dental profession is one of the most stressful health professions. ${ }^{1}$ Stress-related illnesses, together with musculoskeletal disorders, are the main factors that influence dentists' early retirement. ${ }^{2}$ A literature review on potential stressors and coping techniques in dentistry suggests that this stress begins in dental school. ${ }^{3}$ Studies in dental schools around the world have examined sources of stress among undergraduate dental students, ${ }^{4}$ and have indicated a significant increase in stress among dental students during the decades since 1980. Academic factors, such as examinations and faculty relationships with students, were also shown to create considerable amounts of stress. ${ }^{5}$

Some stress is desirable to prevent boredom and understimulation, but the persistence of stress-related symptoms may result in a decrease in mental and/or physical health, diminished efficiency at work or learning, or even substance abuse. Stress is a significant threat that can result in physical and/or mental illness, and may have a significant negative effect on students' performance and professional practice of dentistry. ${ }^{4}$ The major sources of stress that have been reported are the following: examinations, grades, and fear of failure, ${ }^{6,7}$ clinical requirements, ${ }^{6,7}$ limited time for relaxation, ${ }^{6}$
Correspondence: Abdullah MAlzahem King Abdullah International Medical Research Center/King Saud bin Abdulaziz University for Health Sciences/National Guard Health Affairs, Central Region, PO Box 22490, Mail Code I243, Riyadh I |426, Saudi Arabia

Tel +966 I80I IIII

Fax +966 I80I 40I0

Email zahem@yahoo.com 
clinical competitiveness, ${ }^{8}$ and clinical and supporting staff. ${ }^{9}$ These stressors have been categorized into different factors, ie, academic, clinic-related, social, and financial, or a combination of these factors. These stressors affect dental students differently according to their year of study.

Many studies have been conducted in dental schools around the world, ${ }^{7-30}$ including Jordan, Malaysia, Australia, India, Nigeria, Fiji, Japan, Trinidad and Tobago, the US, Israel, Canada, and some European countries. Most of these studies have been cross-sectional surveys using an original version or a modified version of the Dental Environment Stress (DES) questionnaire. The most significant sources of stress among undergraduate dental students differ from one study to another. For example, in Western countries, the most significant stressors are financial ones, ${ }^{26}$ whereas in India the most significant stressors are related to parents forcing their children to study dentistry against their will. ${ }^{13}$ Although each student experiences the stress of professional training somewhat differently, the cumulative effects of these stressors can have a serious impact on students' psychologic health. ${ }^{31}$ In addition, intense interaction between the dentist and patients may precipitate a state of "burnout" that consists of emotional exhaustion, depersonalization, and reduced personal accomplishment. ${ }^{32}$ The burnout syndrome occurs not only as a result of face to face contact, but also as a consequence of chronic stress in general. The Burnout Clinical Subtype Questionnaire, measuring overload, lack of development, and neglect, is proposed as a brief means of identifying the different ways in which this disorder is expressed. ${ }^{33}$ It has been shown that the clinical years are more stressful than the preclinical years; however, clinical instructors create more stress than the treatment of patients. Moreover, uncertainty about dentistry as a career and unhealthy perfectionism may predispose students to stress. ${ }^{34}$ Students who receive support from teachers and other students, both within and outside dental school, have lower adjusted total stress scores on dental stress questionnaires. ${ }^{27}$

As mentioned, the sources of stress among dental students have been reported frequently in the literature; however, only a few articles have studied the impact of year of study on these sources of stress. ${ }^{17,35-37}$ For example, a study in Greece showed that dental students in their first, third, and fifth years showed more stress than second-year and fourth-year students in a 5-year Doctor of Dental Surgery curriculum. The main aim of the current study was to identify the effect of year of study on the level of stress among dental students in a 5-year Bachelor of Dental Surgery curriculum. An additional aim was to identify the main sources of stress in our sample, which was from a religious culture studying in a traditional curriculum.

\section{Materials and methods}

Participants, questionnaire, and procedure

A cross-sectional design was chosen to achieve the objective of the study; this choice was based on the fact that the majority of studies on the subject of stress among dental students using the validated DES questionnaire also used a cross-sectional design.

The survey was performed using a self-report questionnaire to assess the effect of year of study on the level of stress. Our sample consisted of male undergraduate dental students $(n=214)$ with a mean age of 21 years who were enrolled in the College of Dentistry at King Saud University in Riyadh City, Saudi Arabia. Because of the limited number of male students, all students were invited to participate in the study. The College of Dentistry at King Saud University is the oldest and largest dental school in Saudi Arabia and follows a traditional lecture-based 5-year curriculum. The estimated number of students in each class is approximately 75 males. The education system in Saudi Arabia is sex-based, where males and females study in different locations and buildings. Ethical approval to conduct this study was obtained through the internal review board and King Abdullah International Medical Research Center.

A modified version of the US DES questionnaire was used. ${ }^{5}$ The questionnaire contains 38 items to be scored on a sixpoint scale (from $0=$ not stressful to $5=$ extremely stressful). This questionnaire yields scores on five different factors, (ie, Factor-I: a living accommodation factor; Factor-II: a personal factor; Factor-III: an educational environment factor; Factor-IV: an academic factor; and Factor-V: a clinical factor).

The DES questionnaire was delivered by the class leaders to all five classes of male dental students and was filled out anonymously; 214 of the 345 students returned the completed questionnaire (response rate 60.3\%). Students' participation in the survey varied according to year of study, with the highest participation rate by students in their third year (38\%) and the lowest by students in their fifth year (6.5\%), see Table 1 .

\section{Data analysis}

The means and standard deviations were computed for all items and categories. To assess the reliability of the five different factors, we calculated Cronbach's alpha coefficients. These were 0.932 for the clinical factor, 0.917 for the academic factor, 0.878 for the educational environment factor, 0.822 for the personal factor, and 0.853 for the living accommodation factor. 
Table I Number of participants from each study year

\begin{tabular}{llll}
\hline Year of study & Students & $\begin{array}{l}\text { Proportion } \\
\text { of total (\%) }\end{array}$ & $\begin{array}{l}\text { Response } \\
\text { rate (\%) }\end{array}$ \\
\hline First year & 41 & 19.2 & 63.0 \\
Second year & 57 & 26.6 & 83.8 \\
Third year & 83 & 38.8 & 95.4 \\
Fourth year & 19 & 8.9 & 30.1 \\
Fifth year & 14 & 6.5 & 22.6 \\
\hline
\end{tabular}

To identify any significant differences between years in the curriculum, the sources of stress were tested using oneway analysis of variance comparing the level of stress across the different academic years, from year 1 through year 5 . A pair-wise comparison using the post hoc Tukey's test was also conducted to identify pairs of study years that were significantly different. All statistical tests were declared to be statistically significant at a level of 0.05 or less.

\section{Results}

For all sources of stress, the means and standard deviations were computed and placed in order from the highest scores to the lowest scores (see Table 2). On the item level, examinations (3.38 \pm 1.28$)$ and completing clinical requirements $(3.28 \pm 1.51)$ were reported as the highest stressors. The next stressors reported with high scores were references and information resources $(3.07 \pm 1.32)$, insufficient treatment time (3.04 \pm 1.36$)$, and the system of the study $(2.98 \pm 1.40)$.

Table 2 Means, SDs, and 95\% Cls for differences in scores on items of the questionnaire $(n=214)$

\begin{tabular}{|c|c|c|c|c|}
\hline \multirow[t]{2}{*}{ Questionnaire items } & \multirow[t]{2}{*}{ Mean } & \multirow[t]{2}{*}{ SD } & \multicolumn{2}{|l|}{$95 \% \mathrm{Cl}$} \\
\hline & & & Lower & Upper \\
\hline Examinations & 3.38 & 1.28 & 3.21 & 3.56 \\
\hline Completing clinical requirement & 3.28 & $|.5|$ & 3.10 & 3.52 \\
\hline References and information resources & 3.07 & I.32 & 2.89 & 3.24 \\
\hline Insufficient treatment time & 3.04 & 1.36 & 2.87 & 3.26 \\
\hline System of study & 2.98 & 1.40 & 2.79 & 3.17 \\
\hline Differences in opinion between clinical staff & 2.97 & 1.35 & 2.80 & 3.17 \\
\hline Transition from preclinical to clinical staff & 2.87 & 1.36 & 2.70 & 3.08 \\
\hline Competition for grades & 2.85 & 1.29 & 2.68 & 3.02 \\
\hline Difficulty in managing difficult cases & 2.82 & 1.35 & 2.64 & 3.02 \\
\hline Compliance of patients (patients turn up to appointment) & 2.81 & 1.54 & 2.60 & 3.03 \\
\hline Inadequate time for relaxation & 2.79 & 2.02 & 2.51 & 3.06 \\
\hline Confidence in own clinical decision-making & 2.74 & 1.44 & 2.55 & 2.95 \\
\hline Communication with patients & 2.73 & 1.38 & 2.55 & 2.93 \\
\hline Amount of information given & 2.71 & 1.27 & 2.54 & 2.89 \\
\hline Uncertainty about the field of study as a future career & 2.71 & 1.44 & 2.51 & 2.91 \\
\hline Reduced holidays & 2.69 & 1.45 & 2.50 & 2.89 \\
\hline Health hazard at work & 2.68 & 1.40 & 2.50 & 2.88 \\
\hline Rules and regulations at work & 2.66 & 1.43 & 2.47 & 2.86 \\
\hline Difficulty in learning and mastering precision manual skill & 2.66 & 1.34 & 2.48 & 2.85 \\
\hline Adequacy of clinical supervision & 2.54 & 1.44 & 2.34 & 2.74 \\
\hline New curriculum topics & 2.53 & 1.27 & 2.36 & 2.70 \\
\hline Manual dexterity and manual skill & 2.51 & 1.43 & 2.32 & 2.71 \\
\hline Self confidence & 2.40 & 1.43 & 2.20 & 2.60 \\
\hline Conducive environment for teaching & 2.38 & 1.29 & 2.20 & 2.55 \\
\hline Communication with and approachability of staff & 2.37 & 1.37 & 2.18 & 2.55 \\
\hline Teaching language & 2.34 & 1.38 & 2.15 & 2.53 \\
\hline Receiving criticism at work & 2.22 & 1.53 & 2.00 & 2.43 \\
\hline Social demands (married or unmarried, family, social expectation) & 2.16 & $1.7 \mid$ & 1.92 & 2.39 \\
\hline Teaching and communication language at work & 2.12 & 1.45 & 1.92 & 2.31 \\
\hline Financial problems, eg, travel, accommodation, fees, clothes, food & 2.06 & 1.66 & 1.84 & 2.29 \\
\hline Discrimination between students & 1.99 & 1.58 & $\mathrm{I} .78$ & 2.20 \\
\hline Lack of recreation places within accommodation & 1.82 & 1.42 & $1.6 \mid$ & 2.00 \\
\hline Accommodation is not an appropriate environment for study & 1.78 & 1.39 & 1.59 & 1.97 \\
\hline Discrimination by origin, color, or race & 1.75 & 1.69 & 1.52 & 1.98 \\
\hline Living away from home & 1.72 & 1.53 & 1.50 & 1.92 \\
\hline Personal health (chronic disease, drugs, others) & 1.71 & 1.60 & 1.48 & 1.92 \\
\hline Difficulty in making friends & 1.57 & 1.40 & 1.38 & 1.75 \\
\hline Staying with flatmates & 1.54 & 1.36 & 1.35 & 1.72 \\
\hline Total & 2.46 & 0.91 & 2.34 & 2.58 \\
\hline
\end{tabular}

Abbreviations: $\mathrm{Cl}$, confidence interval; SD, standard deviation. 
On the factor level, the highest scores were found for the clinical factor $(2.92 \pm 1.25)$ and academic factor $(2.64 \pm 1.00)$, whereas the living accommodation factor caused the least stress $(1.36 \pm 1.09)$. Third-year students reported greater stress than students in other years $(2.74 \pm 0.71)$, and firstyear students reported the least stress $(1.48 \pm 0.96)$, as shown in Table 3.

One-way analysis of variance shows the scores for factors across years. Scores on the DES were lowest for first-year students $(1.48 \pm 0.96)$ and highest for third-year students $(2.74 \pm 0.71)$. Third-year students had the highest stress scores on the academic factor $(2.93 \pm 0.80)$, the educational environment factor $(2.78 \pm 0.94)$, and the personal factor $(2.47 \pm 1.10)$. However, second-year students had higher scores on the clinical factor $(3.38 \pm 0.99)$, and fourth-year students had the highest relative score on the living accommodation factor $(1.80 \pm 1.09$, see Table 3$)$. DES scores were significantly different across years of study ( $F[4$, $142]=10.70, P<0.01)$. We also analyzed scores for the individual factors. All factors were significantly different across years of study (Factor-I $F[4,141]=3.30, P<0.05$; Factor-II $F[4,142]=3.96, P<0.01$; Factor-III $F[4,141]=9.93$, $P<0.01$; Factor-IV $F[4,141]=8.88, P<0.01$; Factor-V $F[4,139]=18.72, P<0.01)$.

The above-mentioned differences in DES scores were found to be mainly between first-year students and students from the other years. Scores on the educational environment factor, the academic factor, and the clinical factor for firstyear students were lower than the scores for students in the other years.

Results from the post hoc Tukey's test with Bonferroni correction showed significant differences. For the living accommodation factor, there was a significant difference between scores in the third year and the first year (1.095, $P<0.05)$, second year $(1.364, P<0.05)$, and fifth year
(1.024, $P<0.05)$. Scores on the personal factor show a significant difference between the third year and first year (1.502, $P<0.05)$, second year $(1.265, P<0.05)$, and fourth year $(0.970, P<0.05)$. The personal factor showed a significant difference between the fifth year and the first year (1.005, $P<0.05)$. Scores on the educational environment factor show a significant difference between the first year and the second year $(-0.849, P<0.05)$, third year $(-1.588$, $P<0.05)$, fourth year $(-1.288, P<0.05)$, and fifth year $(-1.516, P<0.05)$. In addition, the educational environment factor showed a significant difference between the second year and third year $(-0.739, P<0.05)$. Scores on the academic factor showed a significant difference between the first year and second year $(-1.266, P<0.05)$, third year $(-1.533, P<0.05)$, fourth year $(-1.129, P<0.05)$, and fifth year $(-1.204, P<0.05)$. Finally, scores on the clinical factor reveal a significant difference between the first year and second year $(-2.084, P<0.05)$, third year $(-1.760$, $P<0.05)$, fourth year $(-1.844, P<0.05)$, and fifth year $(-1.944, P<0.05)$. Third-year students reported the most stress compared with other years of study.

\section{Discussion}

The principal aim of this study was to investigate differences in stress levels among dental students across 5 years of their academic curriculum, and the second aim was to identify the most important sources of stress among the students in our sample.

With regard to the principal aim, third-year students generally reported the highest stress levels, while first-year students reported the lowest stress levels. An explanation for this finding is that third-year students are in the transfer phase from the preclinical to clinical years, in which they start to see patients and have to meet clinical requirements. With regard to the second aim, examinations and clinical

Table 3 Stress through years of study: means, standard deviations, and $95 \%$ confidence intervals of the difference of the five factors of the questionnaire $(n=214)$

\begin{tabular}{|c|c|c|c|c|c|c|c|c|c|c|c|c|}
\hline \multirow{2}{*}{$\begin{array}{l}\text { Factor } \\
\text { Year }\end{array}$} & \multicolumn{2}{|c|}{ Factor I } & \multicolumn{2}{|c|}{ Factor II } & \multicolumn{2}{|c|}{ Factor III } & \multicolumn{2}{|c|}{ Factor IV } & \multicolumn{2}{|c|}{ Factor V } & \multicolumn{2}{|c|}{ Total } \\
\hline & $\mathbf{M}$ & SD & $M$ & SD & $\mathbf{M}$ & SD & $M$ & SD & $M$ & SD & M & SD \\
\hline First & 1.51 & I.II & 1.56 & 1.18 & 1.26 & 1.13 & 1.70 & 0.98 & 1.34 & 1.40 & 1.48 & 0.96 \\
\hline Second & 0.99 & 1.07 & 1.65 & 1.05 & 2.18 & 0.99 & 2.87 & 0.94 & 3.38 & 0.99 & 2.43 & 0.75 \\
\hline Third & 1.69 & 1.07 & 2.47 & 1.10 & 2.78 & 0.94 & 2.93 & 0.80 & 3.08 & 0.90 & 2.74 & 0.71 \\
\hline Fourth & 1.80 & 1.09 & 1.94 & 1.11 & 2.62 & 0.87 & 2.74 & 0.93 & 3.13 & 0.91 & 2.56 & 0.79 \\
\hline Fifth & 1.37 & 0.83 & $2.4 I$ & 1.07 & 2.77 & 1.04 & 2.81 & 0.70 & 3.23 & 0.78 & 2.69 & 0.63 \\
\hline \multicolumn{13}{|l|}{$95 \% \mathrm{Cl}$} \\
\hline Lower & 1.54 & & 2.00 & & 2.16 & & 2.58 & & 2.70 & & 2.34 & \\
\hline Upper & 1.87 & & 2.33 & & 2.46 & & 2.85 & & 3.02 & & 2.58 & \\
\hline
\end{tabular}

Abbreviations: Factor I, living accommodation factor; Factor II, personal factor; Factor III, educational environment factor; Factor IV, academic factor; Factor V, clinical factor; $\mathrm{Cl}$, confidence interval; SD, standard deviation; $\mathrm{M}$, mean. 
requirements were reported to be the highest stressors for dental students.

Previous studies have reported that examinations and completing clinical requirements are the highest sources of stress among dental students. . $8,12,16,26,38-45$ These results were confirmed by this study. In addition, previous studies have reported that perceived stress differs by year of study, with the first year and last year producing the most stress for dental students. In contrast with these findings, in our study, the third year of a 5-year lecture-based traditional curriculum was reported as the most stressful, whereas the first year was reported as the least stressful.

Because of differences in response rates, eg, between the third year and fifth year, generalizations from the entire sample should be made with caution. Also, the results for the fourth and fifth years should be interpreted carefully because of the relatively low numbers of participants from these years.

Our findings regarding stress levels in third-year students led us to take a closer look at the curriculum for the first 3 years in order to redistribute or reduce stress in these students. Introducing clinics gradually from the first year onwards might help to reduce stress in third-year students. Examinations and clinical requirements in the curriculum need to be modified to reduce the stress level among dental students. We also suggest incorporating a stress management program into the dental curriculum in order to teach students to deal better with the stress involved in their program.

A limitation of this study is that it did not include information on academic achievement (eg, the grade point average of the students), so we were not able to identify the effect of the different stress factors on academic achievement. However, it has been reported in the literature that academic achievement is negatively affected by higher stress levels among dental students. ${ }^{46}$ Another limitation of this study is that only male students could be involved, due to the local sex-based education system.

Some stress is inherent in studying dentistry. Nevertheless, stress prevention and interventional measures, eg, deep breathing and progressive muscle relaxation, can reduce or eliminate many sources of stress, and appropriate support services should be available for dental students. ${ }^{47}$

Future research should highlight students' level of stress prior to admission, for comparison with stress levels during the different years of study. In this way, it will be possible to identify any increase in the level of stress due to the dental curriculum. Further, research into differences between stress levels among dental students with different personality types (eg, thinker or risk-taker personality types) might bring about new ideas for the development of stress prevention and intervention programs for students. ${ }^{48} \mathrm{~A}$ thinker personality type does not take risks, because of serious worrying about the consequences of their actions, which creates more stress. On the other hand, a risk-taker personality type is more inclined to take risks and not worry about the consequences, so may suffer less from stress.

Future research is needed to resolve the impact of the third-year program on stress in our sample, which might encourage dental educators to distribute educational materials through the dental curriculum in a way that can reduce stress in these students. Further research is recommended using qualitative methods like interviews and focus groups for indepth exploration of sources of stress and how they may be managed best, based on the views of stakeholders. A comparable study including female students should be done by female colleagues who can access the female dental school at King Saud University.

\section{Conclusion}

Third-year undergraduate dental students reported the highest levels of stress, which is the transfer zone from the preclinical phase to the clinical phase of the curriculum, in which dental students start to see patients. This stress could be reduced by reviewing and modifying the dental curriculum and allowing students to have contact with patients more gradually, starting from the first year. To manage the most common sources of stress in dental students, we suggest including stress prevention and intervention programs within the dental curriculum.

\section{Disclosure}

The authors report no conflict of interest in this work. This research is part of a $\mathrm{PhD}$ undertaken under the supervision of Erasmus University Rotterdam, the Netherlands.

\section{References}

1. Cooper CL, Watts J, Kelly M. Job satisfaction, mental health, and job stressors among general dental practitioners in the UK. Br Dent J. 1987;162(2):77-81.

2. Burke FJ. The practice of dentistry: an assessment of reasons for premature retirement. Br Dent J. 1997;182(7):250-254.

3. Alaujan AH, Alzahem AM. Stress among dentists. Gen Dent. 2004;52(5): 428-432.

4. Alzahem AM, van der Molen HT, Alaujan AH, Schmidt HG, Zamakhshary MH. Stress amongst dental students: a systematic review. Eur J Dent Educ. 2011;15(1):8-18.

5. Garbee WH Jr, Zucker SB, Selby GR. Perceived sources of stress among dental students. J Am Dent Assoc. 1980;100(6):853-857.

6. Al-Omari WM. Perceived sources of stress within a dental educational environment. J Contemp Dent Pract. 2005;6(4):64-74. 
7. Heath JR, MacFarlane TV, Umar MS. Perceived sources of stress in dental students. Dent Update. 1999;26(3):94-98.

8. Sanders AE, Lushington K. Sources of stress for Australian dental students. J Dent Educ. 1999:63(9):688-697.

9. Abu-Ghazaleh SB, Rajab LD, Sonbol HN. Psychological stress among dental students at the University of Jordan. J Dent Educ. 2011;75(8): $1107-1114$

10. Ahmad MS, Md Yusoff MM, Abdul Razak I. Stress and its relief among undergraduate dental students in Malaysia. Southeast Asian JTrop Med Public Health. 2012;42(4):996-1004.

11. Acharya $\mathrm{S}$. Factors affecting stress among Indian dental students. J Dent Educ. 2003;67(10):1140-1148.

12. Kumar S, Dagli RJ, Mathur A, Jain M, Prabu D, Kulkarni S. Perceived sources of stress amongst Indian dental students. Eur J Dent Educ. 2009;13(1):39-45.

13. Tangade PS, Mathur A, Gupta R, Chaudhary S. Assessment of stress level among dental school students: an Indian outlook. Dent Res $J$ (Isfahan). 2011;8(2):95-101.

14. Omigbodun OO. Stressors and psychological symptoms in students of medicine and allied health professions in Nigeria. Soc Psychiatry Psychiatr Epidemiol. 2006;41:415-421.

15. Sofola OO, Jeboda SO. Perceived sources of stress in Nigerian dental students. Eur J Dent Educ. 2006;10(1):20-23.

16. Morse Z, Dravo U. Stress levels of dental students at the Fiji School of Medicine. Eur J Dent Educ. 2007;11(2):99-103.

17. Sugiura G, Shinada K, Kawaguchi Y. Psychological well-being and perceptions of stress amongst Japanese dental students. Eur J Dent Educ. 2005;9(1):17-25.

18. Naidu RS, Adams JS, Simeon D, Persad S. Sources of stress and psychological disturbance among dental students in the West Indies. J Dent Educ. 2002;66(9):1021-1030.

19. Dutta AP, Pyles MA, Miederhoff PA. Stress in health professions students: myth or reality? A review of the existing literature. $J$ Natl Black Nurses Assoc. 2005;16(1):63-68.

20. Laurence B, Williams C, Eiland D. Depressive symptoms, stress, and social support among dental students at a historically black college and university. J Am Coll Health. 2009;58(1):56-63.

21. Lopez Rendon JM, Ochoa Garcia JD, Velez Betancur JC. Diagnostico y propuestas de solucion a las causas de estres en los estudiantes de clinica de la Facultad de Odontologia del Instituto de Ciencias de la Salud, C.E.S. [Diagnosis and proposed solutions to causes of stress in students in the clinic of the CES. Health Science Institute Dental School.] CES Odontol. 1990;3(2):83-94. Spanish.

22. Silverstein ST, Kritz-Silverstein D. A longitudinal study of stress in first-year dental students. J Dent Educ. 2010;74(8):836-848.

23. Sgan-Cohen HD. Stress among Israeli dental students: a two-year longitudinal study. Int J Psychosom. 1989:36(1-4):69-71.

24. Sgan-Cohen HD, Lowental U. Sources of stress among Israeli dental students. J Am Coll Health. 1988;36(6):317-321.

25. Dahan H, Bedos C. A typology of dental students according to their experience of stress: a qualitative study. J Dent Educ. 2010;74(2): 95-103.

26. Muirhead V, Locker, D. Canadian dental students' perceptions of stress. J Can Dent Assoc. 2007;73(4):323.

27. Muirhead V, Locker D. Canadian dental students' perceptions of stress and social support. Eur J Dent Educ. 2008;12(3):144-148.
28. Blinkhorn A, Freeman R, Gorter R, et al. Psychological stress in dental students: baseline results from 7 European schools. J Dent Res. 2001;80(4):1155.

29. Gorter R, Freeman R, Hammen S, Murtomaa H, Blinkhorn A, Humphris G. Psychological stress and health in undergraduate dental students: fifth year outcomes compared with first year baseline results from five European dental schools. Eur J Dent Educ. 2008;12(2):61-68.

30. Humphris G, Blinkhorn A, Freeman R, et al. Psychological stress in undergraduate dental students: baseline results from seven European dental schools. Eur J Dent Educ. 2002;6(1):22-29.

31. Stewart DW. Canadian dental students' perceptions of their learning environment and psychological functioning over time. J Dent Educ. 2006;70(9):972-981.

32. Maslach C. Maslach Burnout Inventory Manual. Palo Alto, CA: Consulting Psychology Press Inc; 1996.

33. Montero-Marin J, Skapinakis P, Araya R, Gili M, Garcia-Campayo J. Towards a brief definition of burnout syndrome by subtypes: development of the "Burnout Clinical Subtypes Questionnaire" (BCSQ-12). Health Qual Life Outcomes. 2011;9:74.

34. Henning K, Ey S, Shaw D. Perfection, the imposter phenomenon and psychological adustment in medical, dental nursing and pharmacy students. Med Educ. 1998;32:456-464.

35. Polychronopoulou A, Divaris K. Perceived sources of stress among Greek dental students. J Dent Educ. 2005;69(6):687-692.

36. Pau AK, Croucher R, Sohanpal R, Muirhead V, Seymour K. Emotional intelligence and stress coping in dental undergraduates - a qualitative study. Br Dent J. 2004;197(4):205-209.

37. Pau AK, Croucher R. Emotional intelligence and perceived stress in dental undergraduates. J Dent Educ. 2003;67(9):1023-1028.

38. Polychronopoulou A, Divaris K. A longitudinal study of Greek dental students' perceived sources of stress. J Dent Educ. 2010;74(5):524-530.

39. Grandy TG, Westerman GH, Combs CE, Turner CH. Perceptions of stress among third-year dental students. J Dent Educ. 1989;53(12): 718-721.

40. Rajab LD. Perceived sources of stress among dental students at the University of Jordan. J Dent Educ. 2001;65(3):232-241.

41. Rosli TI, Abdul Rahman R, Abdul Rahman SR, Ramli R. A survey of perceived stress among undergraduate dental students in Universiti Kebangsaan Malaysia. Singapore Dent J. 2005;27(1):17-22.

42. YapAU, Bhole S, Teo CS. A cross-cultural comparison of perceived sources of stress in the dental school environment. J Dent Educ. 1996;60(5):459-464.

43. Bosch JA, Brand HS, Ligtenberg AJM, Bermond B, Hoogstraten J, Amerongen AVN. The response of salivary protein levels and S-IgA to an academic examination are associated with daily stress. J Psychophysiol. 1998;12(4):384-391.

44. Pohlmann K, Jonas I, Ruf S, Harzer W. Stress, burnout and health in the clinical period of dental education. Eur J Dent Educ. 2005;9(2):78-84.

45. Pani SC, Al Askar AM, Al Mohrij SI, Al Ohali TA. Evaluation of stress in final-year Saudi dental students using salivary cortisol as a biomarker. J Dent Educ. 2011;75(3):377-384.

46. Peretz B, Rosenblum A, Zadik D. Stress levels and related variables among dental students in Jerusalem, Israel. Eur J Dent Educ. 1997;1(4): 162-166.

47. Divaris K. The academic environment: the students' perspective. Eur $J$ Dent Educ. 2008;12(1):120-130.

48. Hoad-Reddick G, MacFarlane TV, Gibson VM. Relating personality to interview results and performance in the first year of the dental course. Br Dent J. 1999;186(7):346-352.
Advances in Medical Education and Practice

\section{Publish your work in this journal}

Advances in Medical Education and Practice is an international, peerreviewed, open access journal that aims to present and publish research on Medical Education covering medical, dental, nursing and allied health care professional education. The journal covers undergraduate education, postgraduate training and continuing medical education
Dovepress

including emerging trends and innovative models linking education, research, and health care services. The manuscript management system is completely online and includes a very quick and fair peer-review system. Visit http://www.dovepress.com/testimonials.php to read real quotes from published authors. 